\title{
Sutured tendon repair; a multi-scale finite element model
}

\author{
Shelley D. Rawson - Lee Margetts • \\ Jason K. F. Wong • Sarah H. Cartmell
}

Received: 17 January 2014 / Accepted: 5 May 2014 / Published online: 20 May 2014

(C) The Author(s) 2014. This article is published with open access at Springerlink.com

\begin{abstract}
Following rupture, tendons are sutured to reapproximate the severed ends and permit healing. Several repair techniques are employed clinically, with recent focus towards high-strength sutures, permitting early active mobilisation thus improving resultant joint mobility. However, the arrangement of suture repairs locally alters the loading environment experienced by the tendon. The extent of the augmented stress distribution and its effect on the tissue is unknown. Stress distribution cannot be established using traditional tensile testing, in vivo, or ex vivo study of suture repairs. We have developed a 3D finite element model of a Kessler suture repair employing multiscale modelling to represent tendon microstructure and incorporate its highly orthotropic behaviour into the tissue description. This was informed by ex vivo tensile testing of porcine flexor digitorum profundus tendon. The transverse modulus of the tendon was $0.2551 \pm 0.0818 \mathrm{MPa}$ and $0.1035 \pm 0.0454 \mathrm{MPa}$ in proximal and distal tendon samples, respectively, and the interfibrillar tissue modulus ranged from 0.1021 to $0.0416 \mathrm{MPa}$. We observed an elliptically shaped region of high stress around the suture anchor, consistent with a known region of acellularity which develop $72 \mathrm{~h}$ post-operatively and remain for at least a year. We also observed a stress shielded region close to the severed tendon ends, which may impair collagen fibre
\end{abstract}

S. D. Rawson · S. H. Cartmell ( $\varangle)$

E12, Materials Science Centre, University of Manchester, Oxford Road, Grosvenor Street, Manchester M1 7HS, UK

e-mail: sarah.cartmell@manchester.ac.uk

L. Margetts

School of Earth, Atmospheric and Environmental Sciences, University of Manchester, Oxford Road, Manchester M13 9PL, UK

J. K. F. Wong

Plastic Surgery Research, Stopford Building, University of Manchester,

Oxford Road, Manchester M13 9PT, UK realignment during the remodelling stage of repair due to the lack of tensile stress.

Keywords Finite element modelling · Tendon ·

Homogenisation $\cdot$ Kessler $\cdot$ Multi-scale modelling $\cdot$ Suture

\section{Introduction}

Tendon injury affects approximately 50/100,000 people in the UK per annum resulting from laceration, crush, sporting injuries or degenerative disorders (Clayton and Court-Brown 2008). Hand flexor tendon injury usually results from laceration or crush damage and despite a century of innovation, $25 \%$ of these patients experience a deficit in mobility following tendon repair (Su et al. 2005). Repair is achieved by suturing the defect to rejoin the severed ends, and many suture arrangements have been proposed (Wu and Tang 2013). The current trend is towards strong repairs to permit early active mobilisation which is beneficial to regaining functional motion of the tendon. High strength is achieved by employing locking suture loops to grip onto fibre bundles (Pennington 1979) and by increasing the number of suture strands crossing the defect (Savage 1985). Whilst this benefits strength, the detriment to the tissue due to the presence and arrangement of the suture has received little attention. Since absorbable suture is not favoured (Trail et al. 1989), the effects of suture presence on the tissue are of interest for long-term tissue health.

The failure of the commonly used modified Kessler suture was imaged using X-ray in human cadaver digital flexor tendons, showing total collapse of the locking loops during loading. This demonstrates that locking loops can cause tissue damage, even within the acceptable operating range of $2 \mathrm{~mm}$ gapping (Mashadi and Amis 1991). Wong et al. describes an 
acellular zone due to cell necrosis when suture and tension are present, arising within $30 \mathrm{~min}$ of suturing and remaining at one year post-operatively (Wong et al. 2010). It was hypothesised that the acellular zone arose due to stresses in the tissue. Fibroblasts synthesise collagen and contribute to the mechanical integrity of tendon (Galloway et al. 2013), thus acellular regions are detrimental to both healing and functionality. In light of these studies, the suitability of current suture repairs in providing a mechanically favourable environment for the tissue is questionable.

Acellular tendon regions have been observed in the Kessler suture repair (Wong et al. 2010). Identification of similar acellular regions within the various suture arrangements would aid the surgeon in selecting a repair which provides both mechanical stability and a favourable environment for healing. An in silico model, validated against observations of Wong et al., could be adapted to study the tissue insult resulting from the variety of suture repairs. This will aid suture technique selection for healing and long-term tissue functionality and may be adapted for the prototyping and validation of new repair methods. Benefits of in silico validation include rapid prototyping, reduced cost, and reduced use of animals in line with 3R's guidelines (NC3Rs 2012).

To produce an in silico model of a suture repair, tendon mechanical behaviour must be defined, which is largely influenced by tendon structure. Tendon dry weight is $68.5-88 \%$ type 1 collagen (Koob and Vogel 1987), which self assembles into long supermolecular structures called fibrils (Fraser et al. 1983) whose tensile modulus is 200 to 3,000 MPa as determined by atomic force microscopy (Rijt et al. 2006; Svensson et al. 2010). Fibrils are arranged in aligned fibres, which are in turn arranged into fascicles which form the tendon (Strickland 2005). This highly aligned structure results in an orthotropic material, whose tensile modulus is 350 to $850 \mathrm{MPa}$ in the longitudinal direction as demonstrated by ex vivo tensile testing (Butler et al. 1984; Wren et al. 2001). Transverse tendon modulus has received little attention; human cadaver supraspinatus tendon was found to have a transverse modulus of 1 to $40 \mathrm{MPa}$ (Lake et al. 2010); however, a modulus of $0.157 \mathrm{MPa}$ was obtained during transverse tensile testing of ovine flexor tendons (Lynch et al. 2003). Variation in results may be due to differing anatomical locations and species. The present work employed porcine flexor digitorum profundus (FDP) tendon, a suitable surrogate for human tendon (Havulinna et al. 2011), to determine the transverse modulus and fully define the orthotropic behaviour of the tissue.

Finite element modelling (FEM) has been employed to produce an in silico model of a suture repaired tendon. Since the 1970s, finite element analysis (FEA) has been employed for the study of biomechanics, and tendon tissue has been modelled in a variety of ways. Tendon geometry is commonly simplified to 1D (García-González et al. 2009) or 2D
(Wakabayashi et al. 2003) structures in cases where other interacting tissues are the focus of the study, or where the simplification does not impede results. The material description of tendon is also subject to simplification and is commonly described as isotropic linear elastic. Tendon has also been modelled akin to a fibre reinforced composite; modelling the fibrils and surrounding tissue to study crimp formation (Herchenhan et al. 2012) and the effects of microstructure on Poisson's ratio (Reese et al. 2010).

The aim of the present work is to observe the stress and deformation imposed on the tendon tissue by suture when a force is applied, simulating rehabilitation of the repaired tendon. Finite element (FE) analysis was employed to model a sutured tendon repair subject to tension. The FE model was validated against laboratory results. As part of this study, it was necessary to employ 3D modelling and an orthotropic description of tendon tissue since the suture techniques rely on the anisotropy of tendon and strength of the fibrils to provide repair strength. It was impractical to model all the individual fibrils within the suture repair model due to computational cost. As such, a separate model of tendon microstructure was employed, detailing the fibrils and surrounding tissue. Homogenisation was then performed on the microstructure model, and the resultant orthotropic material description was input into the suture repair model. This is a novel approach for the observation of stress and deformation in suture repaired tendons, not published before in the literature. We hypothesise that acellular regions highlighted in previous studies correlate with regions of high stress in the tissue during loading (Wong et al. 2010).

\section{Methods}

\subsection{Obtaining tendon samples}

Tendons were obtained from porcine fore trotters sourced from a local abattoir less than $24 \mathrm{~h}$ after slaughter. The porcine FDP tendon, which is a suitable surrogate for human FDP tendon (Havulinna et al. 2011), was extracted from the central two toes of the trotters and stored in PBS at room temperature until testing, which was performed the same day.

\subsection{Tendon transverse mechanical behaviour}

Proximal and distal samples were dissected from the harvested tendons, cut to $5 \mathrm{~mm}$ wide and $2 \mathrm{~mm}$ thick using a scalpel and measured using digital vernier callipers $(n=12$; Fig. 1). Sample length was equal to tendon thickness. A rectangular cross section was desired for ease of gripping, removal of the epitenon and to enable calculation of stress and strain. An Instron 5,569 load frame (Instron, High Wycombe, UK) with a $100 \mathrm{~N}$ load cell, adapted to fit Bose serrated tissue 
Fig. 1 Preparation of tendon samples for transverse tensile testing
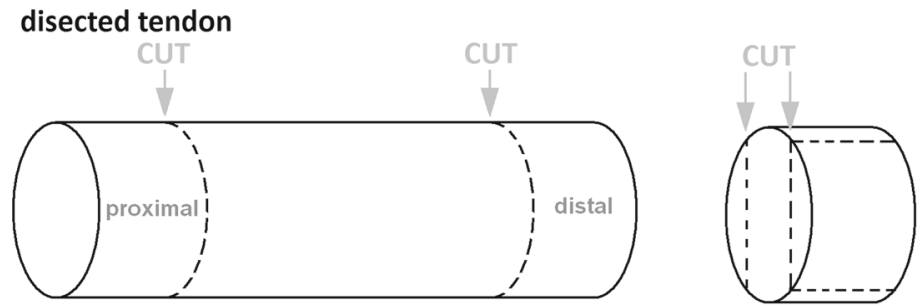

prepared sample
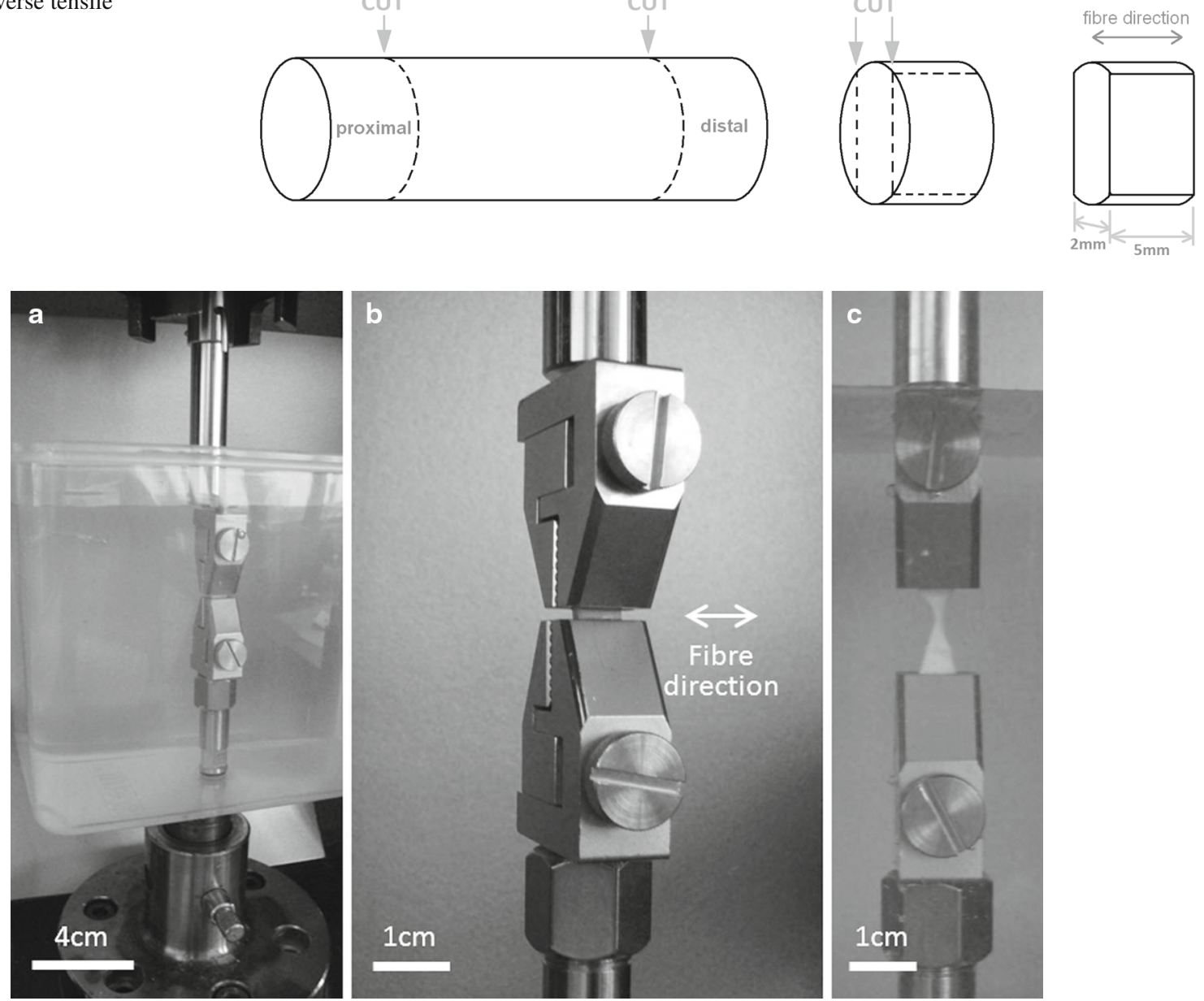

Fig. 2 Tendon loaded in tissue grips prior to transverse tensile testing. a Full apparatus including PBS filled tank. b Sample prior to loading, shown in grips without tank for clarity. c Sample after failure

grips (Bose Corporation, Eden Prarie, Minnesota, USA) was employed for tensile testing. Tissue grips were placed $2.5 \mathrm{~mm}$ apart prior to gripping of each sample, ensuring a consistent initial testing length. No pretension was applied due to the low loads at which the sample failed. Compliance in the system was negligible and thus not accounted for. Samples were tested to failure whilst submerged in Dulbecco's Phosphate Buffer Solution (without Ca2+ or Mg2+; PBS; PAA Laboratories, Pasching, Austria) at a strain rate of 1 and $10 \% / \mathrm{s}$ which represents strain rates during quasi-static conditions and normal daily activity, respectively (Wren et al. 2001; Lewis and Shaw 1997) (Fig. 2). The modulus of the approximately linear region of the stress strain curve was obtained before calculation of the mean.

\subsection{Calculating matrix modulus}

The rule of mixtures was employed to calculate matrix modulus (Eq. 1) (Callister and Rethwisch 2011). Accounting for tissue variation, the fibril and matrix modulus were defined as a range rather than an absolute value. Fibril volume fraction (Vf) was 0.6 (Reese et al. 2010), and the lower and upper limits of fibril modulus (Ef) were 200 and 3,000 MPa, respectively, as defined in literature (Rijt et al. 2006; Svensson et al. 2010). Transverse modulus (ECT) was obtained experimentally (Sect. 2.2), and the lower and upper matrix modulus values $(\mathrm{Em})$ were calculated using Eq. 1. To calculate the lower modulus limit, Ef was assigned the value of $200 \mathrm{MPa}$ and the lower ECT value was used. To calculate the upper modulus limit, Ef was assigned the value of 3,000 MPa and the upper ECT value was used.

$E_{\mathrm{CT}}=\frac{E_{m} E_{f}}{\left(1-V_{f}\right) E_{f}+V_{f} E_{m}}$

2.4 Finite element model of tendon microstructure

Tendon microstructure was assumed to behave akin to a continuous fibre reinforced composite, whose fibres were the 

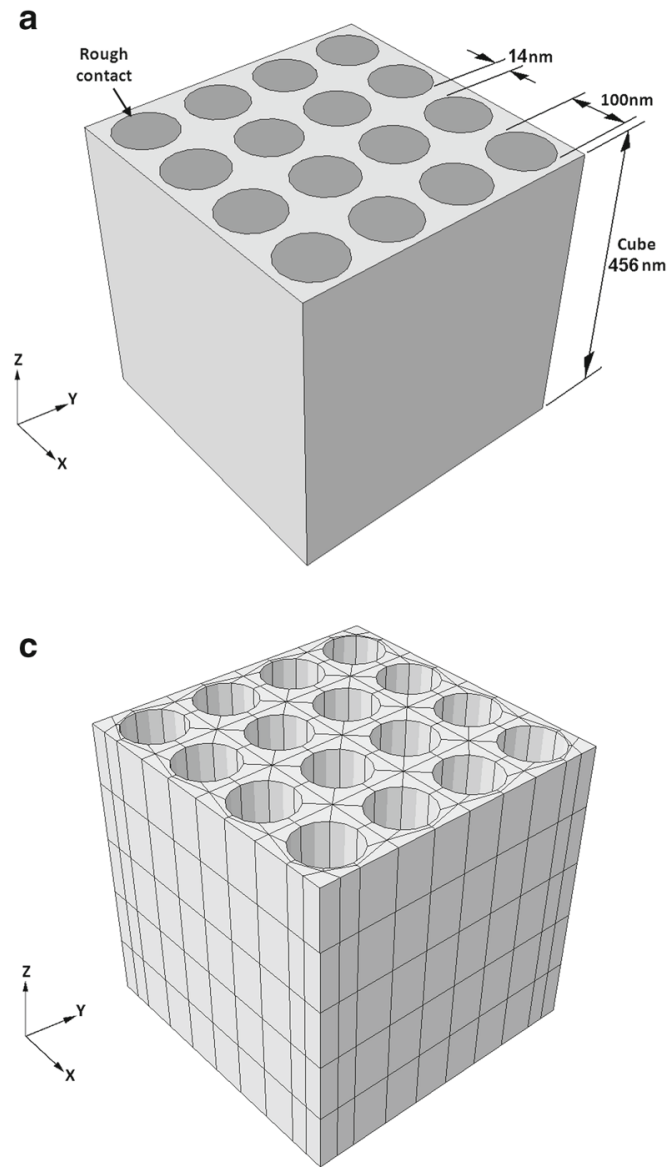
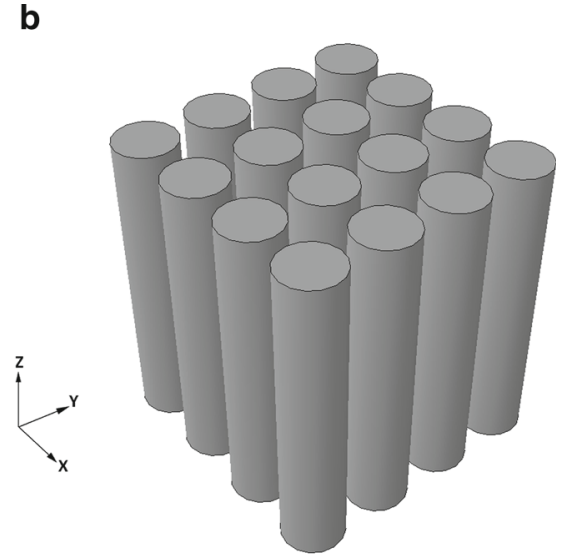

d

Fig. 3 Microstructure finite element model showing geometry of fibrils and matrix (a and $\mathbf{b})$ and Mesh of matrix (c) and fibrils (d)

fibrils, and whose matrix was the surrounding tissue. An idealised FE model of one repeating unit cell was produced using Abaqus (version 6.10; Simulia, Providence, Rhode Island, USA). Fibril volume fraction of approximately 0.6 was employed as described by Reese et al. (2010), and fibril diameter was set to $100 \mathrm{~nm}$, midway between the range of fibril sizes found by Baek et al. (1998) resulting in fibril spacing of $14 \mathrm{~nm}$ (Fig. 3). The dimensions of the repeating unit cell were chosen to be large enough to minimise the stress inconsistencies at the edges whilst still allowing an appropriately sized mesh and not compromising on computational cost. Rough contact was assigned between the fibrils and matrix, and surfaces were not permitted to separate. A mesh of 3D hexahedron quadratic elements with reduced integration (C3D20R) elements was employed with 820 elements in the matrix and 60 elements in each fibril.

Fibrils and matrix were both defined as isotropic linear elastic materials with a Poisson's ratio of 0.3. A fibril modulus of 1,700 MPa was chosen and maintained for all models, as this is within the range or Young's modulus values given in literature (Rijt et al. 2006; Svensson et al. 2010). Matrix modulus was initially set to $1,700 \mathrm{MPa}$ to validate the authors' implementation of the homogenisation method, checking that homogenising mathematically a composite comprising two materials with the same modulus (1,700 $\mathrm{MPa})$ gave a homogenised material with identical modulus (1,700 MPa).

The matrix modulus was then iteratively reduced by an order of magnitude, approaching the value observed experimentally. FE software suffers numerical difficulties (unable to find a solution) when the model incorporates two materials of very different modulus. The first attempt at analysis with the actual experimental values failed due to this issue. The strategy adopted here brought the numerical values used in the FEA as close as possible to the experimental ones. This methodology is broadly accepted in engineering simulation and has been used elsewhere in biomechanics (Herchenhan et al. 2012).

Once the modulus values were determined, homogenisation was performed; two tensile and two shear strains were applied to the microstructure model, the resultant stresses in each direction were obtained and the engineering constants were computed. The engineering constants (the tangential moduli; E1, E2, E3, the Poisson's ratios; v12, v13, $\nu 23$, and the shear moduli; G12, G13, G23) describe the 
Table 1 Homogenisation of the microstructure model using FEA to obtain engineering constants

\begin{tabular}{|c|c|c|c|c|}
\hline & Boundary Condition & $\begin{array}{l}\text { Desired } \\
\text { Engineering } \\
\text { Constant }\end{array}$ & $\begin{array}{l}\text { FE Outputs } \\
\text { Required }\end{array}$ & Equations \\
\hline \multirow{5}{*}{ DISPLACEMENT } & \multirow{5}{*}{$\begin{array}{l}\text { Displacement } \\
\text { Top surface displaced } 45.6 \mathrm{~nm} \text { in -ve } \mathrm{x} \\
\text { direction. } \\
\text { Constraint } \\
\text { Bottom surface unable to move in } \mathrm{x} \text { and } \\
\text { central node of bottom surface unable to } \\
\text { move. }\end{array}$} & E1 & $\begin{array}{l}\text { E.max } \\
\text { S.mises } \\
\text { IVOL }\end{array}$ & $\begin{aligned} \sigma & =\frac{\sum_{i=1}^{n}{\text { S. } \text { mises }_{i} I V O L_{i}}_{\sum_{i=1} I V O L_{i}}}{\sum_{i=1}^{n}} \varepsilon=\frac{\sum_{i=1}^{n} E_{1} \max _{i} I V O L_{i}}{\sum_{i=1}^{n} I V O L_{i}} \\
E_{1} & =\frac{\sigma}{\varepsilon}\end{aligned}$ \\
\hline & & E2 & & $E_{2}=E_{1}$ \\
\hline & & v12 & $\begin{array}{l}\text { E.11 } \\
\text { E.22 }\end{array}$ & $\varepsilon_{1}=\frac{\sum_{i=1}^{n} E \cdot E 11_{i} I V O L_{i}}{\sum_{i=1}^{n} I V O L_{i}} \varepsilon_{2}=\frac{\sum_{i=1}^{n} E \cdot E 22_{i} I V O L_{i}}{\sum_{i=1}^{n} I V O L_{i}}$ \\
\hline & & v13 & $\begin{array}{l}\text { E.33 } \\
\text { IVOL }\end{array}$ & \\
\hline & & v23 & & $v_{12}=-\frac{\varepsilon_{2}}{\varepsilon_{1}} \quad v_{23}=v_{13}=-\frac{\varepsilon_{3}}{\varepsilon_{1}}$ \\
\hline & $\begin{array}{l}\text { Displacement } \\
\text { Top surface displaced } 45.6 \mathrm{~nm} \text { in -ve } x \\
\text { direction. } \\
\text { Constraint } \\
\text { Bottom surface unable to move in } x \text { and } \\
\text { central node of bottom surface unable to } \\
\text { move. }\end{array}$ & E3 & $\begin{array}{l}\text { E.max } \\
\text { S.mises } \\
\text { IVOL }\end{array}$ & $\begin{array}{l}\sigma=\frac{\sum_{i=1}^{n}{\text { S. } \text { mises }_{i} I V O L_{i}}_{\sum_{i=1} I V O L_{i}}}{\sum_{i=1}^{n} I V O L_{i}}=\frac{\sum_{i=1}^{n} E \cdot \max _{i} I V O L_{i}}{\sum_{i}^{n}} \\
E_{3}=\frac{\sigma}{\varepsilon}\end{array}$ \\
\hline $\begin{array}{l}\text { DISPLACEMENT \& } \\
\text { CONSTRAINT }\end{array}$ & $\begin{array}{l}\text { Displacement \& Constraint } \\
\text { Top surface displaced } 45.6 \mathrm{~nm} \text { in } \times \text { direction } \\
\text { and prevented from movement in y } \\
\text { direction. } \\
\text { Constraint } \\
\text { central node of bottom surface unable to } \\
\text { move. }\end{array}$ & G12 & $\begin{array}{l}\text { E.E12 } \\
\text { S.S12 } \\
\text { IVOL }\end{array}$ & $\begin{aligned} \tau & =\frac{\sum_{i=1}^{n} S \cdot S 12_{i} I V O L_{i}}{\sum_{i=1}^{n} I V O L_{i}} \quad \gamma=\frac{\sum_{i=1}^{n} E \cdot E 12_{i} I V O L_{i}}{\sum_{i=1}^{n} I V O L_{i}} \\
G_{12} & =\frac{\tau}{\gamma}\end{aligned}$ \\
\hline $\begin{array}{l}\text { DISPLACEMENT \& } \\
\text { CONSTRAINT }\end{array}$ & $\begin{array}{l}\text { Displacement \& Constraint } \\
\text { Top surface displaced } 45.6 \mathrm{~nm} \text { in } \times \text { direction } \\
\text { and prevented from movement in } \mathrm{z} \\
\text { direction. } \\
\text { Constraint }\end{array}$ & G13 & $\begin{array}{l}\text { E.E13 } \\
\text { S.S13 } \\
\text { IVOL }\end{array}$ & $\begin{array}{l}\tau=\frac{\sum_{i=1}^{n} S \cdot S 13_{i} I V O L_{i}}{\sum_{i=1}^{n} I V O L_{i}} \quad \gamma=\frac{\sum_{i=1}^{n} E \cdot E 13_{i} I V O L_{i}}{\sum_{i=1}^{n} I V O L_{i}} \\
G_{13}=\frac{\tau}{\gamma}\end{array}$ \\
\hline CONSTRAINT & $\begin{array}{l}\text { central node of bottom surface unable to } \\
\text { move. }\end{array}$ & G23 & & $G_{13}=G_{23}$ \\
\hline
\end{tabular}

$\mathrm{En}=$ tangential modulus in the $\mathrm{n}$, direction, $\nu \mathrm{nm}=$ shear moduli $\mathrm{mn}$ direction, $\mathrm{Gmn}=$ shear modulus in the mn direction. All FE outputs are describing behaviour of the integration points, E.max = maximum principal strain, S.mises $=$ Von Mises stress, IVOL $=$ integration point volume, E.Emn $=$ Strain in mn direction, S.Smn $=$ strain mn direction, $\sigma=$ stress in whole volume, $\varepsilon=$ strain in whole volume, $\tau=$ shear stress in whole volume, $\gamma=$ shear strain in whole volume

homogenised orthotropic material behaviour that is representative of the microstructure. This process is detailed in Table 1. Had the material been fully orthotropic, additional tensile and shear analyses would have been necessary to obtain all the engineering constants; however, since tendon is transversely isotropic, some of the tests are effectively identical and would therefore yield the same results.

\subsection{Laboratory Kessler tensile testing}

Tensile tests were performed on full and half repairs (Fig. 4a and $b$ respectively), and no significant difference in tensile strength was observed (data not shown) due to symmetry in the loading arrangement. Half Kessler suture repairs were performed in the tendon samples using 4-0 Prolene suture a

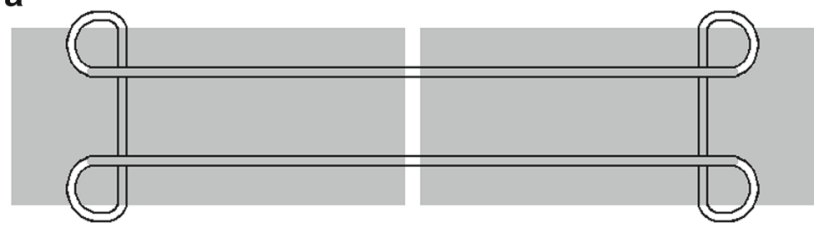

b

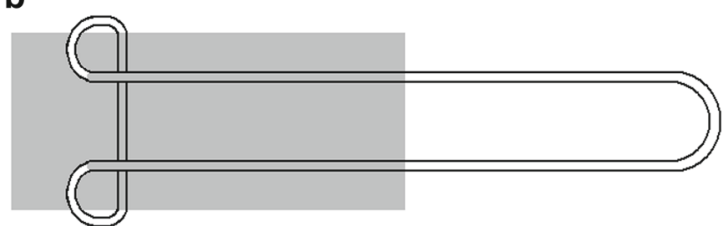

Fig. 4 Schematic of a Kessler suture repair, and $\mathbf{b}$ half Kessler repair $($ Grey $=$ tendon. White and black line $=$ suture external of tendon. Grey and black line $=$ suture internal of tendon) 
(Ethicon Ltd, Edinburgh, UK) ensuring a consistent repair length of $1 \mathrm{~cm}$ (Fig. 4b) $(\mathrm{n}=12)$. Samples were tested in PBS at a strain rate of $1 \% / \mathrm{s}$ using an Instron 5569 load frame (Instron, High Wycombe, UK) adapted to fit a Bose biodynamic tissue grip (Bose Corporation, Eden Prarie, Minnesota, USA) and a custom grip. The tissue grip held the tendon end, and the suture was looped around the custom grip (Fig. 5). A pretension of $0.1 \mathrm{~N}$ was applied to ensure the sample was taut prior to testing. Compliance of the system was assessed by performing a tensile test with a loop of suture spanning the grips. Compliance within the system was subtracted from tensile test results and the mean force with increasing displacement was calculated.

\subsection{Kessler finite element model}

A grasping Kessler suture arrangement, (Fig. 4a) was modelled using Abaqus (version 6.10; Simulia, Providence, Rhode Island, USA). The thickness and width of the modelled tendon were 3.5 and $6.5 \mathrm{~mm}$, respectively, following digital vernier calliper measurement of 10 fresh porcine FDP tendons. Due to symmetry, it was only necessary to construct
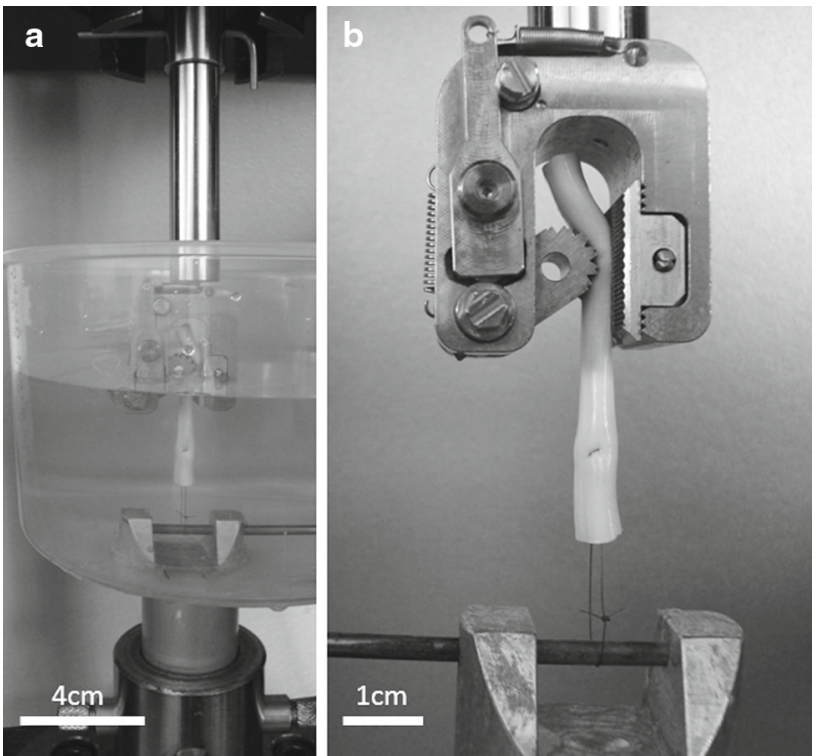

Fig. 5 Half Kessler sutured tendon in Bose tissue grip and custom apparatus prior to tensile testing. a Full apparatus including PBS filled tank. b Sample prior to loading, shown in grips without tank for clarity

b

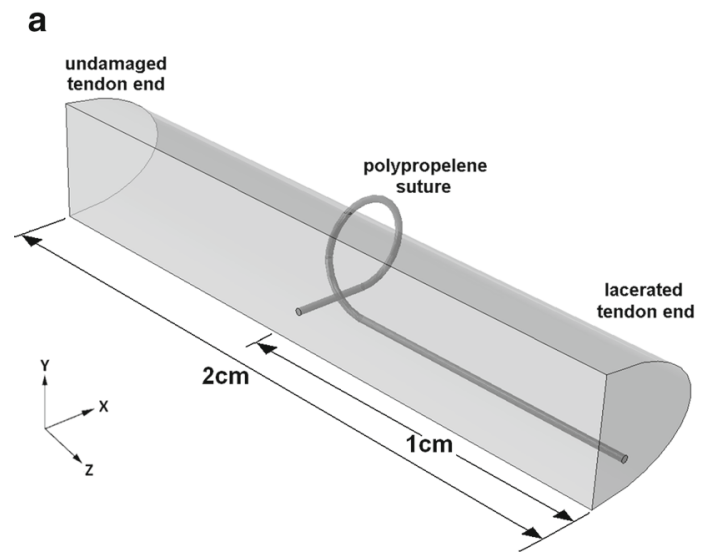

$b$

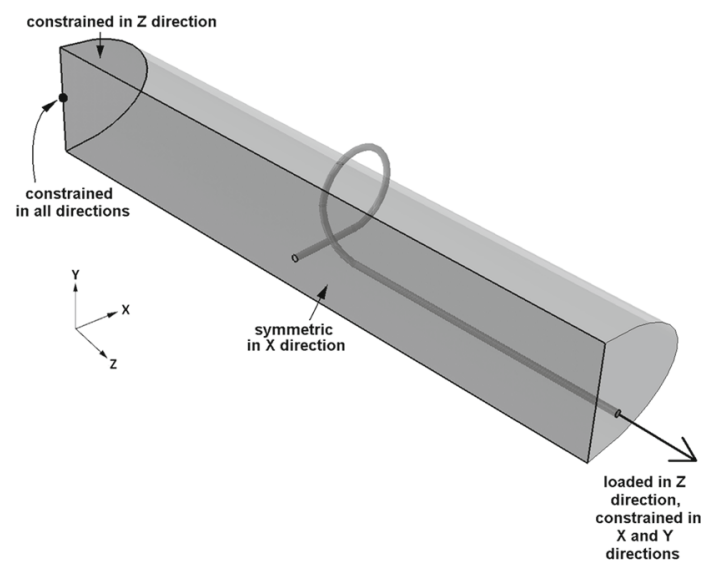

d

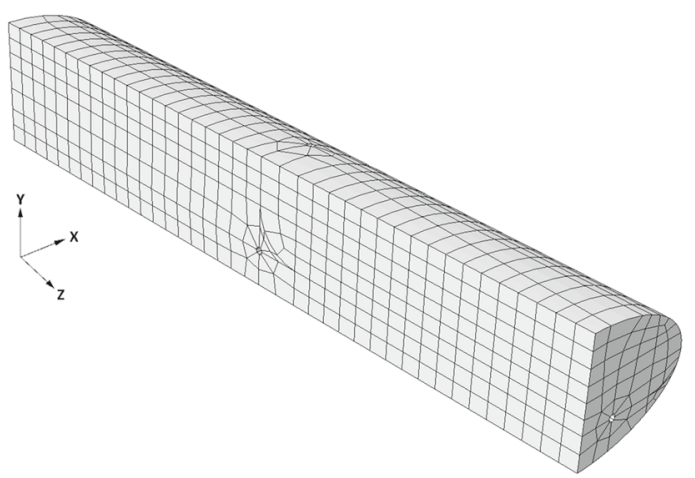

Fig. 6 Finite element model of Kessler suture repaired tendon. a Arrangement of model. b Boundary conditions and load. c Suture mesh. d Tendon mesh 
one quarter of the repair; stress and displacement in the unmodelled region is a mirror image of the results obtained. Suture diameter was $0.2 \mathrm{~mm}$, consistent with the 4-0 Prolene suture used during tensile testing. Three boundary conditions were applied to the tendon as shown in Fig. 6b. A friction coefficient of 0.005 was assigned between the suture and tendon. A mesh of C3D20R elements was employed with 540 elements in the suture and 1963 elements in the tendon (Fig. $6 \mathrm{c}$ and d respectively). The initial state of the suture repair model simulates contact between the tendon ends.

The suture was described as a homogenous linear elastic material with Poisson's ratio of 0.4 and Young's modulus of $1 \mathrm{GPa}$ (Callister and Rethwisch 2011). Isotropic and orthotropic linear elastic descriptions were both employed to describe tendon tissue. For the isotropic model, a Poisson's ration of 0.4 was employed, and Young's modulus was varied between 2,000 and 0.2 MPa. Engineering constants were used to describe the orthotropic model, obtained following homogenisation of the microstructure model.

Increments of load were applied from zero up to a maximum to generate load-displacement curves for comparison with the experimental results (Fig. 7). The curves end at the point where Abaqus had difficulties with solving the system. This arises when some of the FEs become too distorted. A workaround is to continuously remesh the models, but this additional computational effort was not thought to add to the insight. The maximum values of loads achieved follow. A maximum load of $0.1005 \mathrm{~N}$ was applied to the FE isotropic model, and maximum loads of 0.0251, 0.1257, and $0.0628 \mathrm{~N}$ were applied to the FE orthotropic models when matrix modulus was set to 100,10 and $1 \mathrm{MPa}$, respectively. A $0.5 \mathrm{~mm}$ gap between tendon ends was simulated to observe high-stress regions in the tendon tissue.

\section{Results}

\subsection{Tendon transverse modulus, matrix modulus and orthotropic description}

Transverse modulus was independent of strain rate when varied between 1 and 10\%/s. The mean modulus of distal and proximal samples was $0.1035 \pm 0.0454 \mathrm{MPa}$ and $0.2551 \pm$ $0.0818 \mathrm{MPa}$, respectively. Employing the rule of mixtures (Eq. 1), the upper and lower limits of matrix modulus (Em) were calculated as 0.1021 and $0.0416 \mathrm{MPa}$, respectively.

Following homogenisation of the microstructure FE model, the engineering constants are noted in Table 2 whereby direction 3 is parallel with the fibrils. When fibril and matrix modulus were both $1,700 \mathrm{MPa}$, results agree with expected values, validating the homogenisation method.
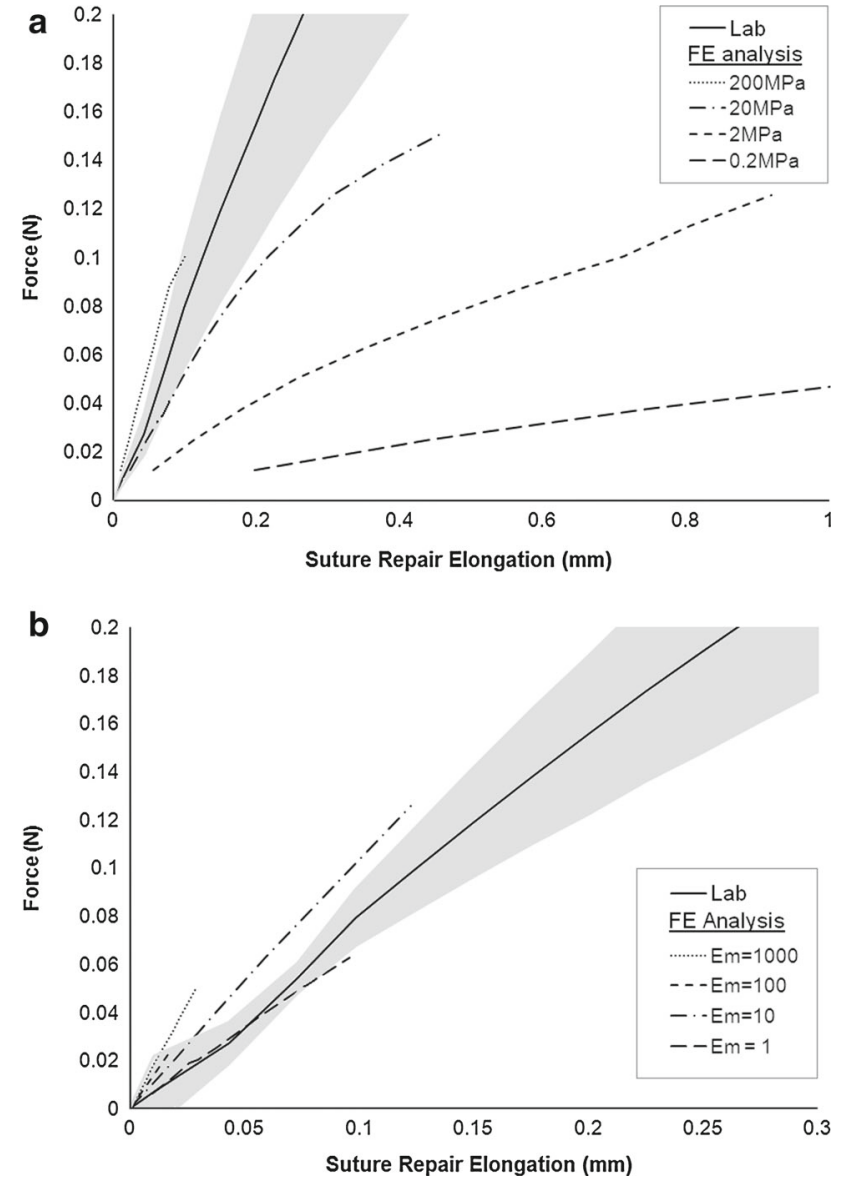

Fig. 7 Half Kessler suture repair, comparing lab results (solid line, showing standard error as the grey shaded region) and finite element analysis results (a) using an isotropic linear elastic material description with Poisson's ratio of 0.4 and varying tendon modulus. b using an orthotropic linear elastic material description with Poisson's ratio of 0.3 , fibril modulus of $1,700 \mathrm{MPa}$ and varying matrix modulus

It was not possible to obtain homogenisation results when the matrix is reduced to $0.1 \mathrm{MPa}$ due to the large difference between the fibril and matrix modulus.

\subsection{Kessler finite element model; varying tendon tissue properties}

Increasing load was applied to the FE Kessler model, and the suture displacement was recorded. A comparison between experimental and FE results when tendon tissue material properties are varied are shown in Fig. 7. When employing a linear elastic isotropic material description of tendon, closest agreement with experimental results is achieved when Young's modulus is $200 \mathrm{MPa}$ and Poisson's ratio is 0.4. The linear elastic orthotropic model agrees closest with experimental results when the young's modulus of the fibrils is $1,700 \mathrm{MPa}$, the modulus of the matrix is between 10 and $1 \mathrm{MPa}$, and Poisson's ratio for both is 0.3 . 
Table 2 Combinations of fibril modulus, matrix modulus and Poisson's ratio used in microstructure model and resultant engineering constants obtained following homogenisation

\begin{tabular}{llllll}
\hline Poisson's Ratio & 0.3 & 0.3 & 0.3 & 0.3 & 0.3 \\
Fibril modulus (MPa) & 1,700 & 1,700 & 1,700 & 1,700 & 10 \\
Matrix modulus (MPa) & 1,700 & 1,000 & 100 & 46.13252132 & 1,700 \\
\hline$E_{1}(\mathrm{MPa})$ & $1,700.170582$ & $1,331.031627$ & 360.6245005 & 4.751048729 \\
$\mathrm{E}_{2}(\mathrm{MPa})$ & $1,700.170582$ & $1,331.031627$ & 360.6245005 & 4.751048729 \\
$\mathrm{E}_{a}(\mathrm{MPa})$ & $1,699.997010$ & $1,360.970271$ & $1,002.429677$ & 966.5762966 & 962.9909984 \\
$\mathrm{~V}_{12}$ & 0.300130459 & 0.298320823 & 0.268011764 & 0.254911608 & 0.253220532 \\
$\mathrm{~V}_{13}$ & 0.300037122 & 0.286305936 & 0.106071965 & 0.032033916 & 0.022529523 \\
$\mathrm{~V}_{23}$ & 0.300037121 & 0.286305936 & 0.106071965 & 0.032033916 & 0.022529523 \\
$\mathrm{G}_{12}(\mathrm{MPa})$ & 653.8461470 & 503.1115299 & 102.8961735 & 11.65915112 & 1.181960429 \\
$\mathrm{G}_{13}(\mathrm{MPa})$ & 653.8461509 & 513.3786443 & 171.9071495 & 60.75475776 & 45.64068793 \\
$\mathrm{G}_{23}(\mathrm{MPa})$ & 653.8461509 & 513.3786443 & 171.9071495 & 60.75475776 & 45.64068793 \\
\hline
\end{tabular}

The engineering constants must be specified to ten significant figures to ensure that the material is fully described

\subsection{Simulation of a $0.5 \mathrm{~mm}$ gap between tendon ends}

Figure 8 shows the resultant deformation and stress map when simulating a $0.5 \mathrm{~mm}$ gap between the tendon ends in the Kessler repair. A high-stress region is observed around the grasping suture loops. As the modulus of the matrix is reduced and the material becomes more orthotropic, the highstress region around the suture loop becomes more elongated along the length of the tendon.

We employ a linear elastic description for tendon behaviour, and it is therefore necessary to ensure this is an appropriate approximation for the tissue response within the range of deformation we apply to our model. Figure 9 shows the average stress-strain curves during transverse tensile testing of the porcine FDP tendon. The peak stress at which these curves behave linearly is 0.16 and $0.1 \mathrm{MPa}$ for proximal and distal samples, respectively. From literature, the peak stress at which the human Achilles tendon, with a tangential modulus of $450 \mathrm{MPa}$, exhibits a linear relationship between stress and strain is $55 \mathrm{MPa}$ (Lewis and Shaw 1997). These values indicate the peak stress, above which a linear elastic material assumption will not represent the tendon behaviour.

The isotropic material model employs a tangential modulus of $200 \mathrm{MPa}$, and a peak stress of $3.56 \mathrm{MPa}$ is reached in the model (Fig. 8a), which is within acceptable limits for the linear material assumption when using longitudinal data (55 MPa). The orthotropic model is derived from the matrix and fibril modulus. Assuming a linear relationship between tangential modulus and peak stress, we deduce a peak stress for a linear assumption in the matrix and fibrils and then employ the rule of mixtures to deduce a peak stress for the homogenised material description employed in each analysis. The peak permissible stress is $156,90,84$ and $83 \mathrm{MPa}$ when the fibril modulus is $1,700 \mathrm{MPa}$ and the matrix modulus is $1,000,100,10$ and $1 \mathrm{MPa}$, respectively. The peak tendon stress in each model is within the limit of linear behaviour for each analysis performed (Fig. $8 \mathrm{~b}$ to d)

\section{Discussion}

The aim of this study was to observe the stress arising in the tendon tissue when load was applied to a sutured tendon repair. It was hypothesised that the high-stress region would agree with an elliptical area of acellularity present following suture repair and load application (Wong et al. 2010). The stress map resulting from isotropic material properties presents a circular high-stress region around the suture anchor (red and orange region on Fig. 8a). The high-stress region tends towards an elliptical shape as the microstructure matrix modulus tends towards $0.1 \mathrm{MPa}$ when the orthotropic tendon description is employed (red and orange region on Fig. $8 \mathrm{~b}$ to d). This supports the hypothesis that the acellular region arises due to high stress when suture and tensile loading are present (Wong et al. 2010). These results also highlight the importance of a suitable material description for tendon when employing FEA. In past sutured tendon analyses, an isotropic material description has been employed (Ingle et al. 2010; Funakoshi et al. 2008); however, results may differ had the highly orthotropic tendon properties been fully represented in the FE models. Simplifications are necessary during FE modelling, and we have employed several assumptions in our model. The suture knot was not modelled, yet this is often the failure location of suture repairs; however, our area of interest is stress in the tendon tissue, not the suture, which would not be affected by this simplification. We have also assumed perfect symmetry and perfect geometry within the repair, along with a perfectly transverse laceration, which is 


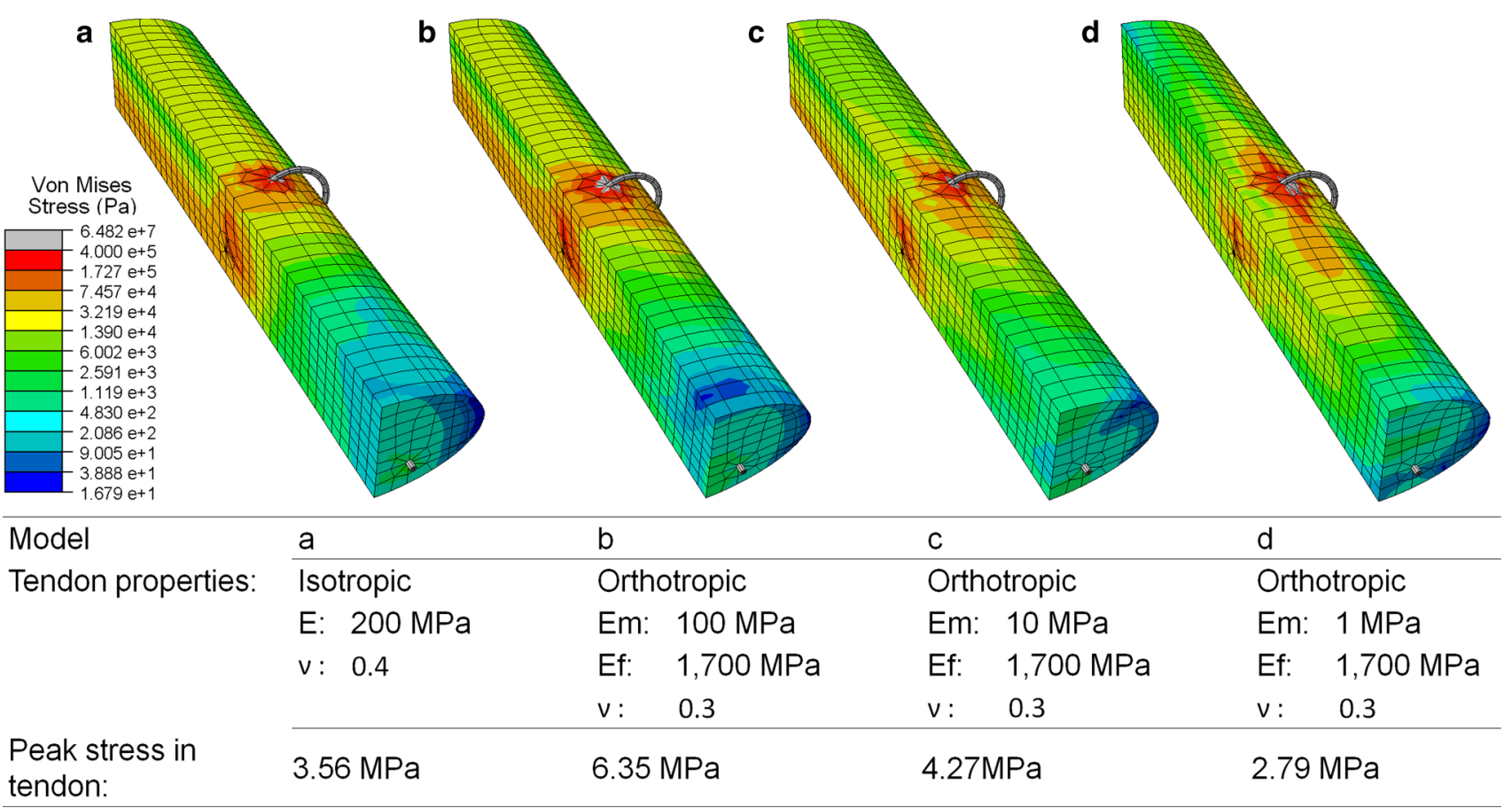

Fig. 8 Deformation and stress map of Finite Element Kessler model when a $0.5 \mathrm{~mm}$ gap between the tendon ends is simulated. Tendon material description and peak stress in the tendon is detailed in the accom- panying table. $\mathrm{E}=$ Young's modulus, $\mathrm{Em}=$ modulus of the matrix, $\mathrm{Ef}$ $=$ modulus of the fibrils, $v=$ Poisson's ratio

restrictive adhesions following early active mobilisation, as opposed to passive mobilisation or immobilisation (Aoki et al. 1994; Wada et al. 2001; Halikis et al. 1997). In vitro tensile loading of stem-cell collagen sponge constructs results in significantly increased failure strength and stiffness compared with unloaded samples after 2 weeks (Juncosa-Melvin et al. 2006) demonstrating the benefits of axial tension. Additionally, the final stage of tendon healing involves realignment of collagen fibrils along the direction of loading which increases strength, thus the failure strength of the healing tissue approaches that of undamaged tendon (Woo et al. 1999). Under normal loading conditions, collagen aligns parallel to the long axis of the tendon (Galloway et al. 2013); however, the augmented stress pattern we observe when a Kessler suture is present (Fig. 8d) may affect realignment of the collagen. Realignment may be impaired in regions of stress shielding, as we observe near the tendon cut end, reducing localised tensile strength. Similarly, the direction of alignment may be altered due to the altered stress pattern throughout the suture site. Whilst an altered alignment of fibres may be suited to withstanding the altered loading environment, this may ultimately contribute to the inferior tensile strength observed in repaired tendon compared with healthy tendon (Burns et al. 2000), increasing the chance of long-term re-rupture.

Laboratory results during loading of a Kessler suture agree closest with isotropic FE results when the modulus is $200 \mathrm{MPa}$ which was expected as this lies between the fibril 
and matrix modulus. When an orthotropic material description was employed, it was expected that FE results would tend towards laboratory results as the matrix modulus tended towards $0.1 \mathrm{MPa}$. Closest agreement is seen when matrix modulus is between 10 and $1 \mathrm{MPa}$. These unexpected results may arise from differences between the tendon microstructure and our idealised model. Assumptions were necessary to minimise computational cost. We have assumed the fibrils to be perfectly cylindrical, of regular cross sectional area, and in alignment with the long axis of the tendon. We did not account for the crimp pattern exhibited by fibrils (Rigby et al. 1959), irregularity and variation in fibril cross section (Starborg et al. 2013), or the effects of cells on the tissue, and we have not included a second level of tendon hierarchy. The impact on bulk properties when varying the microstructure geometry would be of interest to establish which microstructure features are essential and which are negligible when modelling tendon for this application.

Whilst we were able to perform FE analyses with properties approaching those found experimentally, it was not possible to obtain engineering constants when fibril modulus was $1,700 \mathrm{MPa}$ and matrix modulus was $0.1 \mathrm{MPa}$, as measured in the tissue. During homogenisation, large strains would occur at the interface between the two severely different phases resulting in high distortion in the model which cannot be computed. In addition, Tendon is a viscoelastic material (Schwerdt et al. 1980); however, only the elastic behaviour has been accounted for in this model to minimise computing cost. Tendon also possesses a very high Poisson's ratio which is over 0.8 (Cheng and Screen 2007; Lynch et al. 2003); however, Poisson's ratio is limited to 0.5 when using Abaqus and a value close to 0.5 results in a material which is too stiff to sufficiently deform. The low Poisson's ratio employed in this work is thought to have minimal impact on results as the tendon tissue is not excessively constrained. FEA does not provide exact results to a given problem, rather it provides an approximation. To obtain exact results an infinite number of elements would be necessary. As such, mesh effects may have contributed towards the difference between laboratory and expected FE results. Similarly, the homogenisation method does not provide an exact resultant bulk material description; however, it permits representation of the microstructure within the suture repair model, which we have seen impacts on the resultant stress pattern.

Ideally, the length of a tensile test sample would be at least 5 times the width. Sample length was limited by the tendon thickness, and difficulties in cutting a thin slice of fresh tendon using a scalpel. A desirable aspect ratio could have been achieved using a microtome as performed by Lake et al. (2010); however, this involves freezing the tendon which can impact on tendon mechanical properties (Clavert et al. 2001), thus we chose to test unfrozen tissue. Whilst the small aspect ratio we employed will cause error due to stress at the clamps, all samples failed at the mid-substance (Fig. 2) rather than the grip interface.

We have described a method of tendon modelling, suited to observing tendon stress resulting from suture repairs during loading, and demonstrated agreement between the highstress region and acellularity in the tissue. Modelling alternative suture arrangements would permit comparison between acellular regions, without the expense and time required with animal models whilst also complying with the 3R's (NC3Rs 2012). Clinically, this information would inform both suture selection and rehabilitation protocols. The model may also be adapted to analyse specific injuries, for example, obliquely lacerated tendons or those exhibiting tissue degradation as seen in spontaneous rupture (Kannus and Józsa 1991).

Acknowledgments The authors would like to thank the Engineering and Physical Sciences Research Council and the Medical Research Council (grant code MRC:G1000788/1) for funding this research.

Open Access This article is distributed under the terms of the Creative Commons Attribution License which permits any use, distribution, and reproduction in any medium, provided the original author(s) and the source are credited.

\section{References}

Aoki M, Manske PR, Pruitt DL, Larson BJ (1994) Tendon repair using flexor tendon splints: an experimental study. J Hand Surg Am 19:984-990

Baek GH, Carlin GJ, Vogrin TM, Woo SL (1998) Quantitative analysis of collagen fibrils of human cruciate and meniscofemoral ligaments. Clin Orthop Relat Res 357:205-211

Burns J, Kampen J, Kahrs J, Piltz W (2000) Achilles tendon rupture: experimental results on spontaneous repair in a sheep-model. Knee Surg Sports Traumatol Arthrosc 8:364-369

Butler DL, Grood ES, Noyes FR, Zernicke RF, Brackett K (1984) Effects of structure and strain measurement technique on the material properties of young human tendons and fascia. J Biomech 17:579_ 596

Callister WD, Rethwisch DG (2011) Materials science and engineering. Wiley, New York

Cheng VWT, Screen HRC (2007) The micro-structural strain response of tendon. J Mat Sci 42:8957-8965

Clavert P, Kempf JF, Bonnomet F, Boutemy P, Marcelin L, Kahn JL (2001) Effects of freezing/thawing on the biomechanical properties of human tendons. Surg Radiol Anat 23:259-62

Clayton RA, Court-Brown CM (2008) The epidemiology of musculoskeletal tendinous and ligamentous injuries. Injury 39:1338-1344

Fraser RD, Macrae TP, Miller A, Suzuki E (1983) Molecular conformation and packing in collagen fibrils. J Mol Biol 167:497-521

Funakoshi T, Suenaga N, Sano H, Oizumi N, Minami A (2008) In vitro and finite element analysis of a novel rotator cuff fixation technique. J Shoulder Elbow Surg 17:986-992

Galloway MT, Lalley AL, Shearn JT (2013) The role of mechanical loading in tendon development, maintenance, injury, and repair. J Bone Joint Surg Am 95:1620-1628

García-González A, Bayod J, Prados-Frutos JC, Losa-Iglesias M, Jules KT, Becerro De Bengoa-Vallejo R, Doblaré M (2009) Finite-element simulation of flexor digitorum longus or flexor digitorum brevis ten- 
don transfer for the treatment of claw toe deformity. J Biomech 42:1697-1704

Halikis MN, Manske PR, Kubota H, Aoki M (1997) Effect of immobilization, immediate mobilization, and delayed mobilization on the resistance to digital flexion using a tendon injury model. J Hand Surg Am 22:464-472

Havulinna J, Leppänen OV, Järvinen TL, Göransson H (2011) Comparison of modified Kessler tendon suture at different levels in the human flexor digitorum profundus tendon and porcine flexors and porcine extensors: an experimental biomechanical study. J Hand Surg Eur 36:670-676

Herchenhan A, Kalson NS, Holmes DF, Hill P, Kadler KE, Margetts L (2012) Tenocyte contraction induces crimp formation in tendon-like tissue. Biomech Model Mechanobiol 11:449-459

Ingle NP, King MW, Zikry MA (2010) Finite element analysis of barbed sutures in skin and tendon tissues. J Biomech 43:879-886

Juncosa-Melvin N, Shearn JT, Boivin GP, Gooch C, Galloway MT, West JR, Nirmalanandhan VS, Bradica G, Butler DL (2006) Effects of mechanical stimulation on the biomechanics and histology of stem cell-collagen sponge constructs for rabbit patellar tendon repair. Tissue Eng 12:2291-2300

Kannus P, Józsa L (1991) Histopathological changes preceding spontaneous rupture of a tendon. A controlled study of 891 patients. J Bone Joint Surg Am 73:1507-1525

Koob TJ, Vogel KG (1987) Site-related variations in glycosaminoglycan content and swelling properties of bovine flexor tendon. J Orthop Res $5: 414-424$

Lake SP, Miller KS, Elliott DM, Soslowsky LJ (2010) Tensile properties and fiber alignment of human supraspinatus tendon in the transverse direction demonstrate inhomogeneity, nonlinearity, and regional isotropy. J Biomech 43:727-732

Lewis G, Shaw KM (1997) Tensile properties of human tendo Achillis: effect of donor age and strain rate. J Foot Ankle Surg 36:435-445

Lynch HA, Johannessen W, Wu JP, Jawa A, Elliott DM (2003) Effect of fiber orientation and strain rate on the nonlinear uniaxial tensile material properties of tendon. J Biomech Eng 125:726-731

Mashadi ZB, Amis AA (1991) The effect of locking loops on the strength of tendon repair. J Hand Surg Br 16:35-39

NC3Rs (2012) Animal use in the UK [online]. http://www.nc3rs.org. uk/page.asp?id=8 [Accessed 19 March 2014]

Pennington DG (1979) The locking loop tendon suture. Plast Reconstr Surg 63:648-652

Reese SP, Maas SA, Weiss JA (2010) Micromechanical models of helical superstructures in ligament and tendon fibers predict large Poisson's ratios. J Biomech 43:1394-1400

Rigby BJ, Hirai N, Spikes JD, Eyring H (1959) The mechanical properties of rat tail tendon. J Gen Physiol 43:265-283

Savage R (1985) In vitro studies of a new method of flexor tendon repair. J Hand Surg Br 10:135-141
Schwerdt H, Constantinesco A, Chambron J (1980) Dynamic viscoelastic behaviour of the human tendon in vitro. J Biomech 13:913-22

Starborg T, Kalson NS, Lu Y, Mironov A, Cootes TF, Holmes DF, Kadler KE (2013) Using transmission electron microscopy and 3View to determine collagen fibril size and three-dimensional organization. Nat Protoc 8:1433-1448

Strickland JW (2005) The scientific basis for advances in flexor tendon surgery. J Hand Ther 18:94-110

Su BW, Solomons M, Barrow A, Senoge ME, Gilberti M, Lubbers L, Diao E, Quitkin HM, Rosenwasser MP (2005) Device for zone-II flexor tendon repair. A multicenter, randomized, blinded, clinical trial. J Bone Joint Surg Am 87:923-935

Svensson RB, Hassenkam T, Grant CA, Magnusson SP (2010) Tensile properties of human collagen fibrils and fascicles are insensitive to environmental salts. Biophys J 99:4020-4027

Trail IA, Powell ES, Noble J (1989) An evaluation of suture material used in tendon surgery. J Hand Surg Br 14:422-427

Van Der Rijt JA, Van Der Werf KO, Bennink ML, Dijkstra PJ, Feijen J (2006) Micromechanical testing of individual collagen fibrils. Macromol Biosci 6:697-702

Wada A, Kubota H, Miyanishi K, Hatanaka H, Miura H, Iwamoto Y (2001) Comparison of postoperative early active mobilization and immobilization in vivo utilising a four-strand flexor tendon repair. J Hand Surg Br 26:301-306

Wakabayashi I, Itoi E, Sano H, Shibuya Y, Sashi R, Minagawa H, Kobayashi M (2003) Mechanical environment of the supraspinatus tendon: a two-dimensional finite element model analysis. J Shoulder Elbow Surg 12:612-617

Wong JK, Alyouha S, Kadler KE, Ferguson MW, Mcgrouther DA (2010) The cell biology of suturing tendons. Matrix Biol 29:525536

Woo SL, Hildebrand K, Watanabe N, Fenwick JA, Papageorgiou CD, Wang JH (1999) Tissue engineering of ligament and tendon healing. Clin Orthop Relat Res 367:S312-S323

Wren TA, Yerby SA, Beaupre GS, Carter DR (2001) Mechanical properties of the human achilles tendon. Biomech (Bristol, Avon) 16:245251

Wu YF, Tang JB (2013) Recent developments in flexor tendon repair techniques and factors influencing strength of the tendon repair. J Hand Surg Eur Vol 39(1):6-19 